\title{
Fontes imagéticas na poética de Andreas Gryphius ${ }^{1}$
}

Antônio Jackson de Souza Brandão²

\begin{abstract}
Resumo
Pretendemos refletir sobre a utilização de elementos imagéticos e suas fontes na Alemanha do século XVII e demonstrar que a literatura barroca não deve ser entendida como uma poética de experiências pessoais no sentido contemporâneo. Andreas Gryphius, como os artistas inseridos no contexto social do barroco alemão, estava imerso num mar de imagens e tópicas, fazendo largo emprego dessas em seu trabalho poético. Para isso, utilizou como fonte de inspiração não só os auctoritas e os livros de emblemas que circulavam na Europa no século XVII, como também a Bíblia, já que o período também estava impregnado do elemento sacro.
\end{abstract}

Palavras-chave: Andreas Gryphius, Barroco, gênero emblemático, imagem

\begin{abstract}
We intend to reflect on the use of imagetic elements and its sources in German 17th century and to demonstrate that the literature of the Baroque doesn't have to be understood as poetical of personal experiences in the contemporary's sense. Andreas Gryphius, as the inserted artists in the social context of the German Baroque, was immersed in a sea of images and topics, making large use of these in his poetical work. For that, he used as inspired source not only of the auctoritas and some books of emblems that circulated in Europe in 17th century, like the Bible, since the period also be impregnated of the sacred element.
\end{abstract}

Key words: Andreas Gryphius, Baroque, emblematic genre, image

\section{Gryphius e a incipiente literatura alemã}

Andreas Gryphius (1616-1664), um dos maiores autores do Barroco alemão, é natural de

1 Histórico da pesquisa: aspectos da representação poética barroca na Alemanha, a partir de Andreas Gryphius. Apresentado no "Simpósio Nacional Trans-Posições e Trans-Formações. O texto da imagem e a imagem no texto", na Unicamp, com o título "A literatura seiscentista na Alemanha. Andreas Gryphius: representação, vanitas e guerra", em 2005.

2Antônio Jackson de Souza Brandão é mestre (A literatura barroca na Alemanha: representação, vanitas e guerra) e doutor (Iconofotologia do Barroco alemão) em Literatura alemã e fotografia, ambos pela Universidade de São Paulo. Sua área de pesquisa é a recepção imagética de textos extemporâneos, em especial o conceito de iconofotologia (criado por este pesquisador), email: jackbran@jackbran.pro.br 
Glogau, na Silésia (hoje Polônia), região não muito distante da Boêmia, epicentro da Guerra dos Trinta Anos (1618-1648), de onde saiu grande parte dos mais importantes poetas de expressão alemã do século XVII: Martin Opitz, Angelus Silesius (Johannes Scheffler), Hofmann von Hofmannswaldau, Friedrich von Logau.

No entanto, para se conhecer a obra de Gryphius, é necessário, primeiramente, compreender as particularidades em que se insere a literatura alemã do século XVII, a partir de dois aspectos fundamentais daquela sociedade: sua estrutura política e religiosa. Politicamente, não havia uma nação alemã, pois essa era dividida em mais de trezentos estados semi-autônomos e cada um deles governado por um príncipe, bispo ou conde, apesar da aparente unidade transmitida pelo Sacro Império Romano-Germânico, cujo imperador era eleito pelos príncipes mais poderosos - os Eleitores; do ponto de vista religioso, a região foi o berço da Reforma, que mudaria o destino da Igreja Católica e da Europa, provocando uma série de conflitos e guerras.

Literariamente, alguns escritores alemães, desde Martin Opitz, queriam instaurar uma Renascença na Alemanha, nos moldes da ocorrida em outras literaturas europeias, ainda que com um século de atraso. São fundadas as Sprachgesellschaften ${ }^{3}$, cujo objetivo seria "purificar" a língua alemã, bem como estimular as traduções e a criação de obras literárias próprias nos moldes da Antiguidade e da Renascença.

Foram apresentados, traduzidos e imitados como modelos de arte literária, os grandes mestres Petrarca, Ariosto, Tasso; os escritores da plêiade francesa, como Ronsard; Daniel Heinsius e Hugo Crotius dos Países Baixos; os petrarquistas ingleses; verificando o estranho fenômeno de que esse século, caracteristicamente nacionalista, permitiu uma penetração até então inaudita do espírito estrangeiro. (BOESCH, 1967, p. 160)

Entretanto, foi dentro de um contexto perturbado e conflituoso, no século XVII, que a literatura alemã preparava-se para adentrar no mundo do Renascimento europeu, ainda que tardiamente. Muito se falou das causas desse atraso de quase um século em relação às outras nações europeias. Talvez pudéssemos entendê-lo, lembrando que a Reforma

3 Sprachgesellschaften: termo cunhado, no século XIX, para designar academias linguísticas cujos objetivos eram o estudo e o fomento da própria língua e literatura com o objetivo de inseri-las dentro do contexto literário europeu. Dessa forma, serviam-se de traduções das principais obras das literaturas em língua estrangeira para o alemão, além disso buscavam manter a língua alemã distante da influência de línguas estrangeiras. Inicialmente essas academias somente permitiam a presença de nobres, mas isso foi modificando-se aos poucos e começaram a aceitar eruditos burgueses e literatos. As mais conhecidas Sprachgesellschaften eram: a) Die Fruchtbringende Gesellschaften, fundada em 1617, que tinha entre seus membros: Opitz, Birkenm Gyphius, Logau, Hardörfeer; b) Die Deutschgesinnte Genossenschaft fundada em 1643 por Philipp Von Zesen; c) Der Elbschwanenorden fundada em 1660 por Johann Rist; d) Pegnesische Blumenorden. 
absorveu de tal forma o espírito alemão, no século anterior, que mal restou interesse, força ou tranquilidade para o florescimento do renascimento artístico. (cf.: ibidem, p. 161) Tal Renascimento, no entanto, não passou de uma tentativa, visto que os poetas e dramaturgos alemães do período estavam cercados de tendências barrocas presentes em muita regiões da Europa. O mundo e a literatura não ficaram alheios às transformações socioculturais e religiosas do momento. Assim, por mais que tentassem seguir seus predecessores, imitando-os, não conseguiram, pois já estavam inseridos num outro contexto social, distinto do anterior.

É justamente por isso que o Seiscentismo alemão foi duramente criticado pelas escolas literárias alemãs ulteriores. Grimmelshausen, por exemplo, foi considerado, durante muito tempo, a única expressão literária digna de crédito do período, pois os outros não passavam de marinistas e escritores de tragédias artificiais - que sequer tragédias eram, segundo os moldes de Aristóteles - com sua linguagem gongórica e artificial. Em suma, o autor de Simplizissimus é quem teria salvado o século XVII do total fracasso literário. Tais críticos não viram que a vontade de classicismo foi o único traço característico da Renascença alemã, a qual o Barroco ultrapassou. Assim, cada tentativa de aproximar-se da forma antiga expunha a obra (...) a uma reestruturação altamente barroca. (BENJAMIM, 1984, p. 83)

Em relação à tragédia, segundo os preceitos aristotélicos, Benjamim nos diz que o Seiscentismo alemão foi o período em que Aristóteles teve menos influência, pois essa foi buscada no classicismo holandês e no teatro jesuítico (cf.: ibidem, p. 84), acrescentando que

é quase inacreditável que se tenha afirmado que o drama barroco é uma verdadeira tragédia pelo simples fato de que ele evoca os sentimentos de piedade e terror, que Aristóteles considerava típicos da tragédia - sem levar em conta que Aristóteles jamais disse que somente a tragédia podia evocar essas emoções. (ibidem, p. 74)

Sem nos deixar levar pela crítica alemã dos séculos XVIII e XIX contrária a sua expressão barroca, devemos levar em consideração, pelo menos, o papel desempenhado por aqueles autores não só na construção da língua literária alemã - coube a Martin Opitz estabelecer as regras da poética alemã em seu Buch von der deutschen Poeterey, de 1624 -, como também na efetivação da própria Língua Alemã - cujo marco poderíamos dizer foi a tradução da Bíblia por Lutero. 
Há, assim, no período, a valorização e a utilização da língua nacional como expressão literária, visto que a língua utilizada em muitas cortes alemãs era o francês e a língua poética, o latim. Não se deve esquecer de que na Itália já havia um Petrarca e um Dante Alighieri; na Espanha, um Cervantes; um Ronsard, na França; e em Portugal, Camões já publicara Os Lusíadas; assim, aquele grupo pioneiro deveria ter, pelo menos, o mérito da construção do idioma literário alemão moderno, iniciado por Martinho Lutero com sua tradução da Bíblia. Isso é significativo, principalmente se pensarmos que as primeiras obras de Gryphius também foram escritas no idioma de Virgílio (Herodis Furiae et Rachelis lacrymae, de 1634; Dei Vindicis Impetus et Herodis Interitus, de 1635; Parnassus renovatus, de 1636), quando o mesmo ainda estava no Gymnasium em Fraustadt.

\section{Fontes imagéticas}

Pretendemos apresentar e refletir sobre a utilização de elementos imagéticos e suas fontes no século XVII alemão e demonstrar que a literatura conhecida por barroca não deve ser entendida como uma poética de experiências pessoais no sentido contemporâneo. Enquanto esta se baseia na noção da originalidade, na criatividade individual, naquela os temas e conceitos já são preestabelecidos, mormente na filosofia e na retórica antigas. (Cf.: BRANDÃO, 2009, p. 308)

A literatura é, dessa forma, uma representação retoricamente codificada, quando um eu lírico individual cede espaço a um coletivo, seguindo os preceitos sociais vigentes; não há, dessa forma, nem plágio, nem apelo à originalidade, visto que todos os preceitos já estão determinados na fonte retórica dos auctores, cabendo ao poeta a emulação. (Cf.: ibidem, p. 308)

Ao abordarmos um determinado poeta do período como o alemão Andreas Gryphius, podese supor - a partir de seus dados biográficos - que a origem das imagens trabalhadas em sua obra advenha de suas experiências pessoais - como a Guerra dos Trinta Anos ou mesmo do desengaño dominante no período. Devemos nos lembrar, no entanto, de que o poeta valia-se mais dos lugares-comuns e das tópicas do período e dos auctores do que, propriamente, de seus infortúnios.

Andreas Gryphius, como os artistas inseridos no contexto social do Seiscentismo, estará imerso num mar de imagens e tópicas, fazendo largo emprego dessas em sua obra. Para isso, utilizou-se como fonte inspiradora não só dos auctores e dos vários livros de emblemas que circulavam pela Europa no século XVII, como também da própria Bíblia - visto que o período também estará impregnado do elemento sacro. (Cf.: BRANDÃO, 2010, p. 131) 
Buscaremos exemplificar algumas das fontes imagéticas de que Gryphius se serviu em sua lírica que nos servirá de suporte; para isso, servir-nos-emos das tópicas utilizadas pelo autor e de sua fonte retórica, patrística ou bíblica. Evidentemente, não se pretenderá fazer aqui um exaustivo levantamento de textos e exemplos, mas demonstrar que parte da fonte imagética comum ao autor em questão fazia parte de um manancial comum de que grande parte dos autores da arte do século XVII se abastecia.

\section{Vanitas (vaidade)}

Vaidade das vaidades, diz o Eclesiastes, vaidade das vaidades! Tudo é vaidade. $(\mathrm{Ecl} 1,2)$

Uma das palavras/conceitos mais empregados no século XVII foi, seguramente, a que diz respeito ao texto bíblico retirado do livro do Eclesiastes. Não importa a qual posição social se esteja inserido - se nobre, se clérigo, se burguês, se povo -, seu grau de cultura - instruído, culto, doutor, medíocre, ou mesmo analfabeto como a grande maioria -, ou mesmo sua orientação religiosa - se católico ou protestante -, afinal todos se deixavam influenciar não só pela palavra vanitas como por tudo aquilo que se representava a partir desse conceito: independente se o meio escolhido fosse o pictórico, o escultórico ou o poético.

A vanitas deixa de ser uma mera palavra para tornar-se um gênero em que se imiscuíam as expressões artísticas do século XVII. Além disso, demonstrava a relação conflituosa do homem a partir da consciência de sua efemeridade, de sua brevidade, em suma, da

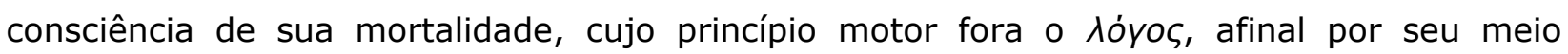
tivemos a consciência de nossa finitude e com ela a angústia de nossa não perenidade.

Artisticamente, vemos a vanitas nas naturezas-mortas às quais foram acrescidas - quando não substituídas - outras imagens plenamente decodificadas pelo homem seiscentista, como o esqueleto inteiro, a caveira, o cálice tombado, a vela apagada, as bolhas de sabão, a ampulheta, entre outras. Na literatura, tivemos as antíteses temporais que também transmitem a efemeridade, ou ainda as mesmas imagens dadas anteriormente que também foram inseridas na poética do período.

Para um leitor contemporâneo de Gryphius, ficaria evidente a influência da Guerra dos Trinta Anos em sua poética, contudo essa será mero mote para expressar a visão da vanitas, já que essa temática é recorrente em outros poetas do período que sequer a presenciaram, 
diretamente, como Quevedo:

Fué sueño ayer, mañana será tierra:/ Poco antes nada, y poco después humo/ $Y$ destino ambiciones y presumo,/ Apenas junto al cerco que me cierra.(...)/Miré los muros de la patria mía,/ Si un tiempo fuertes, ya desmoronados,/ De la carrera de la edad cansados,/ Por quien caduca ya su valentía. (QUEVEDO, 1975, p. 37)

Encontramos vários exemplos da vanitas na obra lírica de Gryphius:

- Ein bald verschmeltzer Schnee und abgebrannte Kerzen. (GRYPHIUS, 1963, v. 1, p. 9)

[Uma neve logo derretida/ e velas queimadas]

- Solt denn die Wasserblaß/ der leichte Mensch bestehn. (GRYPHIUS, op. cit., p. 8)

[Afinal, o leve homem deve ser como a bolha de água?]

- Der jtzt so pocht vnd trotzt/ läst vbrig Asch vnd Bein (GRYPHIUS, op. cit., p. 11)

[Que agora palpita e teima/ então restará pó e osso]

- Uber eine Sand-Uhr/Der Sand der deine Zeit kan in dem Glaß abtheilen/ Weist uns/ wie wir der Grufft/ der Hand voll Sand/ zueilen (GRYPHIUS, 1963, v. 2, p. 206)

[Sobre uma ampulheta/ $A$ areia no vidro teu tempo pode dividir/ nos mostra que da cova nos aproximamos, da mão cheia de areia]

\section{Licht (luz)}

Gryphius empregará Sonne (sol), Licht (luz), erleuchen (clarear), hell (claro), entre outras palavras que indicam luminosidade e claridade, como atributos da divindade que procurará iluminar o homem em busca de sua salvação eterna.

- (...) O dreymal höchste Macht/ Erleuchte den/ der sich itzt beugt vor deinen Füssen! (Gryphius, Sonette, p. 65)

[Ó três vezes altíssimo poder! Ilumina aquele que ora se dobra a teus pés.]

- Kom licht, und scheine dehm, den nacht undt grawen decket. (GRYPHIUS, op. cit., p. 187)

[Vem luz e brilha para aquele que está coberto pela noite e pela cova.]

- Da $\beta$ ich dich/ mein Sonn/ Mein Licht mög ewig schauen. (... ) (GRYPHIUS, op. cit., p. 
65)

[Que eu te veja, meu sol, minha luz, para sempre. ]

- Glantz der Herlikeit, der die sehr lange nacht/ Und alte dunckelheit auff diesen tag volendet! (GRYPHIUS, op. cit., p. 191)

[Ó brilho de majestade, que completa a noite por demais longa e a antiga escuridão nesse dia.]

Gryphius, ao empregar essas imagens, utiliza-se de vasto material fornecido pela Bíblia, tanto do Antigo quanto do Novo Testamento, nos quais a luz é o sinal claro e vivo da divindade ou de sua intervenção, conforme demonstram os exemplos:

- Javé, tu és minha lâmpada: meu Deus tu iluminas a minha treva (SI 18,29)

- O povo que andava nas trevas viu uma grande luz, e uma luz brilhou para os que habitavam um país tenebroso. (Is 9,1)

- Nela [Palavra] estava a vida, e a vida era a luz dos homens. Essa luz brilha nas trevas, e as trevas não conseguem a apagá-la. A luz verdadeira, aquela que ilumina todo o homem, estava chegando ao mundo. (Jo 1,4-9)

Além da tradição bíblica, o sol fora empregado por Horapolo em sua obra Hieroglyphica, uma das fontes dos emblemistas do século XVI muito utilizado por poetas e pintores do século XVII:

Para indicar "eternidad" escriben un sol y una luna porque son elementos eternos. (...) Esta identificación del sol con la eternidad en absoluto debe extrañar, porque ya Platón lo asocia con la imagen de Dios. (HORAPOLO, p. 43)

Cesare Ripa em sua Iconologia assim nos diz:

Mujer que aparece sentada sobre una esfera celeste. Con la diestra sostiene un Sol, junto con sus rayos, y con la siniestra la Luna, con ello se demuestra (...) que el Sol y la Luna son perpetuos engendradores de las cosas, los cuales, por su propia virtud, generan, conservan y dan alimento a todos los cuerpos inferiores (...). (RIPA, 1987, p. 393)

Finsternis (escuridão, trevas)

A escuridão, Finsternis, e seus correlatos dunkel (escuro), Nacht (noite), schwarz (preto) 
demonstram que os homens preferem permanecer sem a graça de Deus, não querem a luz, mas as trevas. Entretanto, o homem será "perseguido" pela luz, já que as trevas não conseguem apagá-la (Jo 1,5). Gryphius também empregará Finsternis como sinônimo do mal, do Príncipe das Trevas:

- Der Furst der funsternus, mitt weh', ach, angst undt leidt!/Schaw wie mich hatt umbhült die nacht der traurikeit (GRYPHIUS, op. cit., p. 189)

[O príncipe das trevas, com dor, ai, medo e sofrimento! Vê como me envolve a noite da tristeza.]

- Vertreit die dicke Nacht/ die meine Seel umbgibt/Die Schmertzen Finsternü $\beta /$ die Hertz und Geist betrübt (GRYPHIUS, op. cit., p. 65)

[Espanta espessa noite que envolve minh'alma; a escuridão de dores que afligem coração e espírito.]

Finsternis e Nacht podem conter outras significações como medo, ou a ausência da divindade.

\section{Korn (grão/semente)}

A semente representa a palavra de Deus que é lançada para encontrar um solo favorável para desenvolver-se e crescer. Este solo é o coração humano, que pode ou não deixar-se ouvir por ela; se se deixar dará muitos frutos; se não, ficará sozinha e estéril.

- Kein körnlein ist so Klein/ als Senff vor uns zu schätzen/Doch/ wenn es in die Scho $\beta$ der feuschten Erden fällt/So wurtzelts eilend ein/ und keinet in die WeltVnd wird ein hoher Baum/ de rund umb allen Plätzen (...) (GRYPHIUS, op. cit., p. 195)

[Nenhuma semente é tão pequena e por nós valorizada quanto a da mostarda, mas quando ela cai no ventre da terra úmida rapidamente cria raízes e brota no mundo, tornando-se uma árvore alta.]

Gryphius retira de Mateus a comparação entre a semente e a palavra de Deus:

O reino do céu é como uma semente de mostarda que um homem pega e semeia no seu campo, embora ela seja a menor de todas as sementes, quando cresce, fica maior do que outras plantas. (Mt $13,31-32)$

Entretanto, há ainda em Mateus a palavra do semeador: 
O semeador saiu para semear. Enquanto semeava, algumas sementes caíram à beira do caminho, e os passarinhos foram e as comeram. Outras sementes caíram em terreno pedregoso, onde não havia muita terra. (Mt 1, 1-3)

Gryphius vale-se agora do evangelho de São João, citando a semente de trigo:

- Wenn nicht das Weitzen-Korn/ ins Grab der Erden fällt/Und sich den schnellen Zahn der Fäule läst verzehren/So kan es keine Blüt/ auch keine Frucht gewehren (...) (GRYPHIUS, op. cit., p. 236)

[Se o grão de trigo não cair no túmulo da terra e se deixar consumir pelo rápido dente da podridão, também não poderá fornecer frutos nem flores.]

O texto de São João: "Eu garanto a vocês: se o grão de trigo não cai na terra e não morre, fica sozinho. Mas se morre, produz muito fruto" (Jo 12,24), juntamente com o de São Mateus que trata do mesmo tema servirá, inclusive, de mote para que Padre Vieira escrevesse seu Sermão da Sexagésima:

O trigo que semeou o pregador evangélico, diz Cristo que é a palavra de Deus. Os espinhos, o caminho e a terra boa em que o trigo caiu, são os diversos corações dos homens (...). Finalmente, a terra boa são os corações bons ou os homens de bom coração; e nestes prende e frutifica a palavra divina, com tanta fecundidade e abundância, que se colhe cento por um: 'Et fructum fecit centuplum'.

Com essas palavras, São João mostra qual será o destino de Jesus: a morte, pois é por meio dela que o Redentor dará a vida pela humanidade. Entretanto, o Messias impele seus discípulos que façam o mesmo, mas para isso esses precisam renegar sua vida - de prazeres, de luxúria, de hipocrisia - para conquistar a vida plena, a vida eterna:

Quem tem apego à sua vida, vai perdê-la; quem despreza a sua vida neste mundo, vai conservá-la para a vida eterna. Se alguém quer servir a mim, que me siga. $E$ onde eu estiver, aí também estará o meu servo. (Jo 12,26)

Gryphius prossegue em seu soneto, mostrando-nos o resultado da fidelidade ao chamamento/seguimento de Cristo, pois apesar da Schmach [humilhação], Angst [medo] e Todt [morte], estaremos no Freundenreiche [o Reino da Felicidade]: 
- Wer Christo treulich folgt/ wer durch Schmach/ Angst/ uñ Streiche/Und Todt ihm ähnlich wird/ sol' in dem Freudenreiche /In Ehren/ Lust und Wonn' ihm ewig gleiche seyn. (Gryphius, op. cit., p. 236)

[Quem segue fielmente a Cristo; quem por humilhação, medo e reveses e morte se lhe torna semelhante e deve ser eternamente semelhante em honra, prazer e felicidade.

\section{Rose (rosa), Blume (flor)}

A rosa será um dos temas recorrentes na poética do Seiscentismo, Gryphius também a empregará, já que ela surge bela com o raiar do dia e, à noite, fenece, demonstrando, assim, a concepção da vanitas. A seguir um exemplo retirado da Trauerspiel Catharina Von Georgien:

- (..) die edlen Rosen leben/so kurtze Zeit/ und sind mit Dornen doch umbgeben./Alsbald die Sonn' entsteht/ schmückt sie der Gärte Zelt;/Vnd wird in nichts verkehrt so bald die Sonne felt.

[As nobres rosas vivem um tempo tão curto e são envolvidas por espinhos. Assim que o sol se levanta, enfeitam o jardim; e transformam-se em nada tão logo o sol se põe.]

Temos também um exemplo retirado do livro de odes:

- Wie eine Rose blühet/ Wen man die Sonne sihet/ Begrüssen diese Welt:/ Die ehr der Tag sich neiget/ Eh sich der abend zeiget/ Verwelckt/ und unversehens abfält (...) (GRYPHIUS, 1963, v. 2, p. 19)

[Como uma rosa floresce, quando vê o sol cumprimentar esse mundo; e antes do dia terminar, antes da noite se mostrar, murcha e cai repentinamente.]

Esse tema também é largamente explorado pela Bíblia:

- Todo ser humano é erva e toda sua beleza e como a flor do campo: a erva seca, a flor murcha, quando sobre elas sopra o vento de Javé; a erva seca, a flor murcha, mas a palavra do nosso Deus se realiza sempre. (Is 40,6-8)

- Olhem como crescem os lírios do campo: eles não trabalham nem fiam. Porém eu Ihes digo: nem o rei Salomão, em toda a sua glória, jamais se vestiu como um deles. Ora, se Deus assim veste a erva do campo, que hoje existe e amanhã é queimada no forno (...). (Mt 6, 28-30) 
Junto à rosa, há espinhos (Dornen) que a rodeiam:

- Kein Stand/ kein Ort/ kein Mensch/ ist seines Creutzes frey/Wo schöne Rosen Blühn/ stehn scharffe Dorn darbey. (GRYPHIUS, 1963, Sonette, v. 1, p. 8)

[Nenhuma classe, nenhum lugar, nenhum homem está livre de sua cruz. Onde florescem belas rosas, estão os espinhos agudos.]

- Mit Thränen grüssen wir/ In Thränen lebt man hir:/ Mit Thränen gibt man gute Nacht!/ Was ist der Erden Saal?/ Ein herber Thränen-Thal! / Wie Rosen die wir zihn/Auff Dörnern nur verblühn. (Gryphius, Oden und Epigramme, v. 2, p. 36)

[Saudamos com lágrimas e em lágrimas se vive aqui: com lágrimas se dá boa-noite! O que é o salão da terra? Um amargo vale de lágrimas, assim como as rosas que cultivamos: só defloram sobre espinhos.]

Segundo Ambrósio (séc. IV d.C.), a rosa rodeada de espinhos representava a condição humana após a expulsão do homem do paraíso, significaria Welt Wollust (prazer mundano). (Cf. JÖNS, 1966, p. 120) Esse é justamente o nome do soneto cujos versos (Kein Stand...) foram transcritos acima: Der Welt Wollust ist nimer ohne Schmerzen [O prazer mundano jamais é sem dor]. Ambrósio recorreu ao Gênesis:

A terra produzirá para você espinhos e ervas daninhas, e você comerá a erva dos campos. Você comerá seu pão com o suor do seu rosto, até que volte para a terra, pois dela foi tirado. Você é pó, e ao pó retornará. (Gn 3, 18-19)

Para Picinelli em seu emblema 177, rosa e espinho significariam Vita humana e no emblema 214, Felicitas mundana (Cf.:ibidem, p. 121); Ripa, por seu lado, mostra-nos os espinhos para retratar a compunção:

Tiene los ojos vueltos hacia el Cielo y vierte copiosas lágrimas, llevando em la cabeza una corona de punzantes espinas. Sostiene con la izquierda un corazón, coronado de espinas igualmente (...) Tiene además dos coronas de espinas (...) [y] representa la culpa contraída por el pecado; culpa que sin cesar punza y remuerde la conciencia, quedando simbolizada por la corona que en la cabeza lleva. (RIPA, op. cit., pp. 205-206)

Gryphius também compara a rosa com Cristo, especificamente como se fosse seu cetro, ou seja, sua autoridade: 
- (...) er wird der Armen Recht/ der müden tröster seyn/ er wird was krum' ist schlecht/ was dunckel offenbar/ was langsam eilends schlichten/ er ist den Rosen gleich/ sein Scepter stärckt und bricht/ gleich wie ein Rosen-Zweig wol reucht/ und hefftig sticht. (Gryphius, 1963, Sonette, v. 1, p. 239)

[(...) ele será consolador do direito dos pobres e dos cansados; ele melhorará o que está torto e mau; tornará claro que está escuro; o que é lento, será apressado. Ele é como as rosas: seu cetro fortalece e quebra; assim como um galho de rosa é perfumado e fere com intensidade.]

Cristo é visto aqui como soberano imparcial, misericordioso e justo, daí a correspondência feita com a rosa, que exala perfume refrescante, mas possui espinhos que podem ferir. No emblema 211, Picinelli havia expressado como mote de um emblema sobre as rosas: Pungit \& recreat; e quando se referiu à natureza de Deus, essa característica da rosa significava Justitia \& Misericordia. (Cf.: Jöns, p. 124)

\section{Schatten (sombras)}

As sombras, na alegoria cristã, representam o Antigo Testamento e essa significação pode ser sob dois pontos de vista: ser somente uma imagem escura; ou como escuridão que desaparece assim que a luz se aproxima (Cf.: Ibidem, p. 120)

No primeiro caso representa o tempo em que a Lei estava na expectativa da revelação divina da salvação; no segundo, uma analogia entre a Lei, o anúncio do Redentor, e o Evangelho, a realidade de sua chegada. As duas perspectivas estarão presentes na obra de Gryphius:

- Der Schatten nimt ein End/ Die alte Prophecey wird durch diss Kind erfüllet. (Jöns, op. cit., p. 191)

[A sombra acaba; a velha profecia se realiza por meio dessa criança.]

- Der Bund ist Neu' und erhellet/ Was der Alte vorgestellet:/Dort sind Schatten: Hir steht klar/ Was dort nur abgebildet war. (Gryphius, Oden und Epigramme, v. 2, p. 104) [A aliança é nova e esclarece o que a velha apresentou. Lá há sombras: aqui está claro o que lá só era representado.]

Vemos exemplos dessa significação no Novo Testamento:

- Estes, porém, realizam um serviço que é imitação e sombra da realidade 
celestes (...). ( $\mathrm{Hb} 8,5)$

- A Lei possui apenas uma sombra dos bens futuros, e não a realidade concreta das coisas. (Hb 10,1)

- Ninguém, pois, julgue vocês pelo que comem ou bebem, ou por causa das festas anuais, mensais ou de sábados. Tudo isso é apenas sombra daquilo que devia vir. A realidade é Cristo. (Col 2, 16-17)

Gryphius também nos passa a ideia de futilidade e de fugacidade, quando emprega Schatten:

- Ach! Was ist alles dis was wir vor köstilich achten/ Als schlechte nichtkeit/ als schatten staub und windt. (GRYPHIUS, Sonette, v. 1, p. 33)

[Ah! Que é tudo isso que julgamos nobre senão futilidade ruim, sombra, pó e vento?]

Meer und Seefahrt (Mar e viagens marítimas)

Frequentemente utilizados nas literaturas do Renascimento e do Barroco, as metáforas náuticas (Schiff [navio], Sturm [tempestade], Fische [peixes], Port [porto], Ufer [costa] são uma tradição da Antiguidade clássica, da patrística e das alegorias bíblicas medievais, mantendo-se por um longo tempo. (Cf. : CURTIUS, 1996, p. 178)

O navio no mar, cercado por sofrimentos e preocupações, mostra-nos a vida do homem no mundo:

- Wie ohne Ruh'/ Ein Schifflein wird bald her/ bald hin geschimissen:/So setzt uns zu/ Der Sorgen Sturm/ wir werden hingerissen/ Auff dises Lebens Schmertzenvollen See. (Gryphius, Oden und Epigramme, v. 2, p. 11)

[Assim sem descanso, o barquinho é jogado para lá e para cá: ataca-nos a tormenta dos problemas, somos arrastados para o mar de dores dessa vida.]

A viagem pelo mar tempestuoso da vida e sua chegada ao porto, apesar de este ser a morte, que deve ser vista como o destino da alma no sentido cristão, e, além disso, será o fim das lamentações, sofrimentos e privações que a vida oferece:

- Mein offt bestürmbtes Schiff der grimmen Winde Spil/ Der frechen Wellen Baal/ das schir die Flutt getrennet/ Das vber Klip auff Klip'/ vndt Schaum/ vndt Sandt 
gerennet;/ Komt vor der Zeit an Port/ den meine Seele wil (...) (GRYPHIUS. Sonette, v. 1, p. 61)

[Meu barco várias vezes atacado pelo jogo voraz dos ventos; o baile das ondas que dividem as águas; que passou por encostas e espuma e areia, chega ao porto antes do tempo; o porto que minh'alma quer.]

Ou ainda quando o poeta fala da morte de sua mãe:

- Gott Lob! Der rauhe Sturm führt durch die wüste See/ Der rasend-tollen Welt/ wo immer neues Weh/ Und Leid auf Angst sich Häufft/ wo auf das harte Knallen/Der Donner/ alle Wind in Flack und Seile Fallen/ Von kaum erkennter Klipp' und seichtverdecktem Sand;/ Mein Schiff (zwar vor der Zeit) doch an das liebe Land. (GRYPHIUS. Vermischte Gedichte. 1964, v. 3, p. 133)

[Louvado seja Deus! A tempestade rude leva-nos pelo mar revolto do mundo louco-irado, onde a dor sempre renovada e sofrimento e medo se acumulam, onde após o estouro do trovão, todo o vento cai nas ondas e velas diante de quase imperceptíveis encostas e areias levemente cobertas. Meu barco (antes do tempo, é verdade) chega à terra amada.]

O mar pode ser a imagem da vida e do mundo; a imagem alegórica cristã vê um navio no mar como representação da Igreja, o mesmo diz Lauretus: Nauis quandoque significant Ecclesiam. (JÖNS, p. 201)

- AVff! Auff/ wach auff HErr Christ/ schau wie die Winde toben!/ Wie Mast und ruder knackt/ itzt sinckt dein Schiff zu grund/ Itzt schaumt die wilde Flutt wo Flack und Segel stund/ Vns fehlts an Stärck und Raths! Bald kracht die Lufft von oben (...) (GRYPHIUS. Sonette, v. 1, p. 194)

[Vamos! Vamos! Acorda Cristo Senhor, vê como os ventos bramem! Como o mastro e o remo estalam, agora o teu barco afunda; agora as águas espumam onde antes havia vela e corda! Faltam-nos força e conselho! Logo estalará o ar de cima (...).]

Há, na Bíblia, vasto material que nos remetem à temática:

- Então Jesus entrou na barca, e seus discípulos o acompanharam. E eis que houve grande agitação no mar, de modo que a barca estava sendo coberta pelas ondas. Jesus, porém, estava dormindo. (Mt 8, 23-24)

- Todos os rios correm para o mar, e o mar nunca transborda; embora cheguem ai fim 
do percurso, os rios sempre continuam a correr. (Ecl 1,7 )

\section{Brunnen und Quelle (poço e fonte)}

Tais imagens, recorrentes na linguagem bíblica, pertencem ao maravilhoso hebraico-cristão e referem-se à essência, à graça de Deus. Por serem bens preciosos, fonte de vida, principalmente numa região desértica, encaixam-se perfeitamente para designar a graça e a divindade, como demonstram os seguintes exemplos:

- Pois em ti se encontra a fonte da vida e com a tua luz nós vemos a luz. (SI $36,10)$

- (...) o meu povo praticou dois crimes: abandonaram a mim, fonte de água viva, e cavaram para si poços, poços rachados que não seguram a água .(Jr 2, 13)

- Por que você se contamina com os cadáveres e é contado ente os que vão para a mansão dos mortos? É porque você abandonou a fonte de sabedoria. $(\mathrm{Bc} 3,12)$

Gryphius também nos transmite essas imagens em sua obra poética:

- Quell der Lieb und Lebens! (Gryphius, Oden und Epigramme, v. 2, p. 107) [Ó fonte do amor e da vida!]

- Wahrer Liebe Fewr! Brunn aller gutten Gaben! (...)/ O wesentliches Liecht! O tewre Gnaden-Quell/ Die du den zarten Leib Mariens hast befeuchtet. (Gryphius, Sonette, v. 1, p. 5)

[Ó fogo do verdadeiro amor! Fonte de todas as bênçãos! Ó luz essencial! Ó cara fonte do perdão que fecundaste o frágil corpo de Maria]

\section{Tiere (animais)}

Em relação aos animais, encontramos, na lírica de Gryphius, uma interpretação mais espiritualizada. Temos os exemplos do bicho-da-seda e do pássaro engaiolado, havendo ambos conotação alegórica. (JÖNS, p. 218) Aquele é utilizado como alegoria desde Basílio, como representação da morte e ressurreição, por meio de sua metamorfose; este representa a prisão da alma pelo corpo.

Além disso, o bicho-da-seda, ao cobrir-se com seu próprio fio, prepara sua própria morte, sendo também símbolo do avaro e, ao mesmo tempo, protótipo do homo mundanus: 
- Die können nichts als Rauch/ und Ruhm ohn Ruhm erwerben/Vnd müssen endlich schnell mit ihrem Schatz verderben/ Gleich als ein Seiden Wurm/ an dem verdorrten Ast/ Sich selbst in Faden spinnt; und sich mit sich umbfast (...) (ibidem, p. 219)

[Eles não podem adquirir nada além de fumaça e fama sem fama e devem logo arruinar com seu tesouro tal como um bicho-da-seda, no galho ressecado, se entretece em fios e se envolve consigo mesmo.]

O bicho-da-seda não simboliza o homem que trabalha para sua própria ruína, mas significa a futilidade de todo esforço e capacidade humana, que somente se preocupa em acumular tesouros na terra. Gryphius tratará desse tema em sua ode Vanitas Mundi:

- Das kleine Thir/ Das Seiden spinnt/ verstrickt sich in seinen spinnen:/ So müssn wir durch unsern Fleiß/ offt unsern Tod gewidmen./ Vil hat Verstand/ und was uns weise macht;/ Ins Grab gebracht. (ibidem, p. 220)

[O pequeno bicho que tece seda enreda-se em seu tecer. Assim devemos nós, através de nosso esforço, nos dedicar freqüentemente a nossa morte; muitos foram levados pela razão, e pelo que nos torna sábios ao túmulo.]

Gryphius também nos remete ao pássaro engaiolado, cuja imagem é utilizada desde a segunda metade do século XV na pintura, bem como na iconografia religiosa:

- Ein Vogel der verschrencket/ Im festen Käficht steckt iemehr Begier ihn lencket/ Nachdem/ was Freyheit heißt: Je härter kommts ihn an/ Wenn er sein enges Hauß gantz nicht erbrechen kan. (ibidem, p. 223)

[Um pássaro preso numa gaiola é levado por um desejo: por aquilo que se chama liberdade; mais duro é para ele quando não consegue quebrar sua apertada casa]

Os outros animais utilizados por Gryphius não são considerados alegorias, mas representações metafóricas como o cordeiro ( $\operatorname{lamm}$ ), o leão (Löwe) e a pomba (Taube). O cordeiro e o sol são as iconografias mais conhecidas de Cristo. João Batista é quem primeiro atribui a Jesus o conceito:

- Eis o cordeiro de Deus, aquele que tira o pecado do mundo. (Jo 1, 29)

- Vocês foram resgatados pelo precioso sangue de Cristo, como o de um cordeiro sem defeito e sem mancha. (1Pd 1,19) 
Gryphius utiliza a imagem do cordeiro na seguinte ode:

- Wonne! Wonne über Wonne!/ Gottes Lamb ist unser Sonne;/ Freude/ Freud' ohn alles Leiden!/ Niemand kan von Gott uns Scheiden. (Gryphius, Oden und Epigramme, v. 2, p. 90)

[Regozijo! Regozijo sobre regozijo! O cordeiro de Deus é nosso sol; alegria, alegria sem sofrimento! Ninguém no pode separar de Deus.]

Entretanto, o cordeiro não é a única metáfora para Cristo, temos também a do leão, vencedor da morte e do demônio:

- O Leão da tribo de Judá, o Rebento de Davi venceu! (Ap 4, 5)

- Existem três seres com belo porte (...): o leão, o mais valente dos animais, que não recua diante de ninguém. ( $\mathrm{Pv} 30,30)$

O leão é representativo, pois pode significar tanto Cristo quanto o demônio. Para Horapolo, o leão representa:

a) Coragem:

Cuando quieren expresar "coraje", pintan un león; pues este animal tiene la cabeza grande, las pupilas como de fuego, la cara redonda y en torno a ella cabellos semejantes a rayos como imitación del sol (HORAPOLO, p. 103)

b) Força física e realeza:

(...) fue llamado de los Griegos León, o porque significa Rey, o porque el león tiene perfectísima vista, y leo significa ver.. Es este Príncipe y Rey de los animales; así por ligereza y fuerza, como por su ferocidad y nobleza, y así comúnmente ha sido símbolo o jeroglífico de los Reyes. (ibidem, p. 105)

c) Vigilância:

Sin duda esta asociación del león con la vigilancia se relacionó con la naturaleza divina de Cristo, quien a modo de león, pasó por el sepulcro sin alterarse. (Ibidem, p. 107) 
d) Temeridade:

El sentido de fortaleza que produce temor ya queda patente en los clásicos (...) mediante un grabado del siglo XVI (...). Aquí, el animal aparece como el más poderoso, el rey de los animales y, se le asocia a la imagen de Cristo como triunfante león espiritual de la tribu de Judá (...). (ibidem, pp. 110-111)

Gryphius utilizará essas metáforas em:

- Wo ist der Höllen Raub? Wo sind de $\beta$ Todes Pfeyle?/Wo ist der Sünden Macht? Wo ist der Schlangen Zahn?/ Wo ist de $\beta$ höchsten Zorn? Wo ist der Höllen Kahn?/ Verjagt! erlegt! entzwey! Wo sind die starcken Seile

Mit den die Sünde band? Ist in so kurzer weile/ De $\beta$ Teufels Reich zustört? Ja! Schaut die Sieges Fahn/ Der Löw und Lamb/ der Knecht und König hats gethan:/ O Leben! Heil! Triumph! auff/ auff mein Herz und eile! (GRYPHIUS, Sonette, v. 1, p. 202)

[Onde está o espólio do inferno? Onde estão as lanças da morte? Onde está o poder dos pecados? Onde está o dente da serpente? Onde está a ira do altíssimo? Onde está o barco do inferno? Afugentado! Morto! Destruído! Onde estão as cordas fortes que amarravam o pecado: será que em tão pouco tempo o reino do Demônio foi destruído? Sim! vede a bandeira da vitória do leão e do cordeiro, o servo e o rei o fizeram. Ó vida! Viva! Triunfo! Vai e corra meu coração!]

Gryphius mostra-nos que Cristo pode ser ao mesmo tempo Lamb, manso, terno e doce, como também Löw, feroz, vigilante e temível, pronto a defender as almas que estão em perigo, destruindo o reino de Satanás. Entretanto, como Horapolo havia dito, o leão também pode ser la personificación de Satán que trata de destruir al bondadoso (HORAPOLO, op., cit., pp. 110-111), o que podemos constatar na Primeira Carta de São Pedro:

- Sejam sóbrios e fiquem de prontidão! Pois o diabo, que é o inimigo de vocês, os rodeia como um leão que ruge, procurando a quem devorar. $(1 \mathrm{Pd} 5,8)$

Gryphius também se utiliza dessa metáfora:

- Mensch wach/ und nim dich in acht!/ Weil Sathan umb dich Tag und Nacht/ 
Im Irrgang dieser Welt/ Als ein hei $\beta$-ergrimmter Lew/ Als ein Mörder ohne scheu/ Manch si're Seel' anfällt' (...). (Gryphius, Oden und Epigramme, v. 2, p. 108)

[Alerta, homem! E cuidado! Pois Satã te ataca dia e noite nos meandros dessa vida como um leão feroz, como assassino sem pudor que ataca muita alma firma.]

- Gib nicht/ was du hast müssen sau'r erwerben/ Dem Tier zur Beutt? Hilff da $\beta$ mich nicht verzehr/ Der grimme Löw. Vertreib den Höllen Beer/ Und la $\beta$ mich Platz in deinem Stall ererben. (Gryphius, Sonette, v.1, p. 203)

[Não dês aquilo que conseguiste com dura labuta; ao bicho como presa? Ajuda-me para que não me coma o leão. Espante o urso do inferno e deixa-me herdar um lugar em teu estábulo.]

Também presente no imaginário cristão será a pomba, que é o símbolo do Espírito Santo:

E João testemunhou: 'Eu vi o Espírito descer do céu, como uma pomba, e pousar sobre ele [Jesus]. (Jo 1,32)

Apesar disso já estava presente no Antigo Testamento:

- Esperou mais sete dias, e soltou de novo a pomba fora da arca. (Gn 8, 10)

- Quando a mulher tiver terminado o período de purificação (...) levará ao sacerdote (...) um cordeiro de um ano para o holocausto, e um pombinho ou rola pelo sacrifício pelo pecado. (Lv 12,6)

Wind (vento)

Há aqui outra representação da vanitas:

- Was ist die Welt/ Die mich bis her mit jhrer pracht bethöret?/ Wie plötzlich felt/ Was Alt und Jung/ und Reich und Arm geehret!/ Was ist doch alles was man allhir findt?/ Ein leichter Wind! (Gryphius, Oden und Epigramme, v. 2, p. 10)

[Que é o mundo que até aqui me enreda com sua beleza? Quão rápido falta o que a jovens e velhos, ricos e pobres louvaram! Como é tudo o que encontramos aqui? Apenas um leve vento!] 
- So werden wir verjagt gleich wie ein Rauch von Winden. (GRYPHIUS, Sonette, v.1, p. 9)

[Assim seremos enxotados tal qual uma fumaça pelos ventos.]

Para Lauretus, vento significava Gloria transitoria; para Alanus de Insulis, de fluxus vitae humanae por transitoriae vitae prosperitas até res transitoria. (Cf.: JÖNS, p. 241)

Podemos encontrar a mesma ideia no Antigo Testamento:

- $\quad$ Os terrores caem sobre mim, a minha dignidade se dissipa como vento, e a minha felicidade se desfaz como nuvem. (Jó 30,15)

- Lembrava-se de que eles eram apenas carne, um vento que se vai, para nunca mais voltar. (SI 78, 39)

\section{Considerações finais}

Gryphius, como os artistas inseridos no contexto social do Seiscentismo, não só estará imerso num mar de imagens e tópicas, como fará largo emprego delas em sua obra como ficou demonstrado acima. Para isso, utilizou-se de todo o acervo imagético de que dispunha no momento: as iconologias, livros de emblemas, a Bíblia, entre outros. Além disso, o poeta também participa do processo criativo e de autoafirmação da língua alemã que, no século XVII, foi dinâmico e contínuo, pois

os escritores esforçavam-se por apropriar-se pessoalmente da força imagística interna, da qual deriva, em sua precisão e em sua delicadeza, a linguagem da metáfora. Seu ponto de honra não era o uso de frases metafóricas, e sim a criação de palavras metafóricas, como se seu objetivo imediato fosse, ao inventar as palavras da poesia, inventar as palavras da língua. (BENJAMIN, pp. 77-78)

Para que ocorresse essa metaforização da língua, a Bíblia, como vimos, teve importante papel no período, servindo mesmo de base para os livros de emblema, das iconologias e mesmo da obra de Horapolo, sendo muito explorada por Gryphius. Há poemas seus que são verdadeiras paráfrases de textos bíblicos. São João, por exemplo, até poderia ser considerado um grande emblemista, pelo emprego que fez das imagens, o exemplo é quando, em seu evangelho, chama o Filho de Deus de Verbum (Jo 1,1-5), ou ainda nas várias imagens criadas no Apocalipse.

Vimos com isso que se torna muito difícil ler textos do período se não tivermos acesso aos 
conceitos por eles empregados, o que pode levar-nos a formular uma interpretação equivocada, desconexa e distante daquilo que o poeta propunha e, diante disso, perpetuarmos os preconceitos.

\section{Referências}

ARISTÓTELES. Os pensadores: Aristóteles. São Paulo: Nova Fronteira, 1996.

BENJAMIM, Walter. Origem do drama barroco alemão. São Paulo: Brasiliense, 1984.

BOESCH, Bruno (Org.). História da Literatura alemã. São Paulo: Herder, 1967.

BRANDÃO, Antônio Jackson de S. "O gênero emblemático", in Travessias (UNIOESTE), v. 07, Cascavel, 2010.

. "Sistemas de representação na arte barroca", in Eutomia: Revista online de Literatura e Linguística, v. 2, Recife, 2008.

\section{A literatura barroca na Alemanha. Andreas Gryphius:} representação, vanitas e guerra. Dissertação de mestrado apresentada à Universidade de São Paulo, 2003.

CURTIUS, Ernst Robert. Literatura européia e Idade Média Latina. São Paulo, São Paulo: Hucitec/Edusp, 1996.

GRYPHIUS, Andreas. Gesammtausgabe der deutschsprachigen Werke (hrsg. Marian Szyrocki): Sonnete. Tübingen: Max Niemeyer, 1963, v. 1, 273 p.

- Gesammtausgabe der deutschsprachigen Werke (hrsg. Marian

Szyrocki) : Oden und Epigramme. Tübingen: Max Niemeyer, 1964, v. 2, 244 p.

- Gesammtausgabe der deutschsprachigen Werke (hrsg. Marian

Szyrocki) : Vermischte Gedichte. Tübingen, Max Niemeyer, 1964, v. 3, 217 p.

. Werke in einem Band. Leipzig, Aufbau Verlag, 1987. 
Hegner, 1962.

Wenn mir der Himmel bleibt - Gedicht. Köln, Verlag Jacob . Weltgeschick und Lebenszeit: Ein schlesicher Barockdichter aus

deutscher und polnischer Sicht (hrsg. Von der Stiftung Gerhart-Hauptmann-Haus). Düsseldorf, Droste Verlag, 1993.

JÖNS, Dietrich Walter. Das sinnen-Bild: studien zur allegorischen Bildlichkeit bei Andreas Gryphius. Stuttgart: J.B. Metzlersche Verlagsbuchhandlung, 1966.

HORAPOLO. Hiroglyphica. Madrid, Ediciones Akal, 1991.

MARAVALL, José Antonio. A cultura do Barroco: análise de uma estrutura histórica. São Paulo: Cultrix, 1997.

RIPA, Cesare. Iconología (Prólogo de Adita Allo Manero)Tomo I. Madrid, Akal, s/d. . Iconología - Tomo II. Madrid: Akal, 1987.

QUeVEdo, Francisco de. Antología Poética. Madrid: Espasa-Calpe, 1975.

SZYROCK, Marian. Andreas Gryphius: Sein Leben und Werk. Tübingen: Max Niemeyer, 1964. 